\title{
Dental Care during COVID-19 Outbreak: A Web-Based Survey
}

\author{
Melissa Faccini ${ }^{1}$ Fernanda Ferruzzi ${ }^{2}$ Aline Akemi Mori ${ }^{2}$ Gabriela Cristina Santin ${ }^{1}$ \\ Renata Cristina Oliveira ${ }^{1}$ Ricardo Cesar Gobbi de Oliveira ${ }^{1}$ Polyane Mazucatto Queiroz ${ }^{3}$ Samira Salmeron ${ }^{4}$ \\ Nubia Inocencya Pavesi Pini² Daniel Sundfeld ${ }^{2} \quad$ Karina Maria Salvatore Freitas ${ }^{1, \odot}$
}

1Department of Orthodontics, Ingá University Center Uningá, Maringá, Brazil

${ }^{2}$ Department of Prostodontics and Restorative Dentistry, Ingá University Center Uningá, Maringá, Brazil

${ }^{3}$ Department of Oral Radiology, Ingá University Center Uningá, Maringá, Brazil

${ }^{4}$ Department of Periodontics and Implant Dentistry, Ingá University Center Uningá, Maringá, Brazil

Eur J Dent:2020;14(suppl S1):S14-S19

\begin{abstract}
Address for correspondence Karina Maria Salvatore Freitas, DDS MSc, PhD, Department of Orthodontics, Ingá University Center Uningá, Rod PR 317, 6114, Maringá, Paraná 87035-510, Brazil (e-mail:kmsf@uol.com.br).
\end{abstract}

\begin{abstract}
Keywords

- COVID-19

- pandemic

- dental care

- emergencies

- dentistry

Objective This survey aimed to assess the effects of coronavirus disease 2019 (COVID-19) on elective and urgency/emergency dental care and dentists concerned. Materials and Methods A web-based survey was performed using Google forms questionnaire sent to dentists in Brazil. Questions included: personal information, type of dental care provided during quarantine, if emergencies increased, the dental office biosafety routine, among others. The levels of concern about the impact of quarantine on dental care and patient oral health conditions and the economic impact on dental practices were evaluated using a 0 - to 10 -point scale. Statistical analysis included descriptive, percentages, one-way ANOVA, Tukey, and chi-square tests.

Results During quarantine, $64.6 \%$ of the dentists attended only urgency/emergency treatments, while $26.1 \%$ maintained routine appointments, and $9.3 \%$ closed the dental offices. A higher percentage of dentists from the least affected states continued routine dental treatment; dentists were younger and presented a significantly lower level of concern about dental treatments and oral health conditions of their patients. An increase in urgency/emergency procedures was reported by $44.1 \%$ of the dentists, mostly due to the unavailability of routine/elective dental care and increased patient anxiety and stress. The main causes of urgency/emergency appointments were toothache, dental trauma, and broken restorations, besides the breakage of orthodontic appliances and temporomandibular disorders. Dentists reported a high level of concern about the economic impact caused by quarantine.

Conclusions The pandemic/quarantine has negatively affected the clinical routine. Personal protection/hygiene care must be adopted and reinforced by dental professionals/staff to make dental procedures safer.
\end{abstract}

DOI https://doi.org/ $10.1055 / \mathrm{s}-0040-1715990$ ISSN $1305-7456$. (c) 2020. European Journal of Dentistry.

This is an open access article published by Thieme under the terms of the Creative Commons Attribution-NonDerivative-NonCommercial-License, permitting copying and reproduction so long as the original work is given appropriate credit. Contents may not be used for commercial purposes, or adapted, remixed, transformed or built upon. (https://creativecommons.org/licenses/by-nc-nd/4.0/)

Thieme Medical and Scientific Publishers Pvt. Ltd., A-12, 2nd Floor, Sector 2, Noida-201301 UP, India 


\section{Introduction}

The novel coronavirus (severe acute respiratory syndrome coronavirus 2 or SARS-CoV-2) is the virus responsible for the infection called coronavirus disease 2019 (COVID-19) (coronavirus disease). ${ }^{1}$ The manifestation of COVID-19 started in Wuhan (China) and has spread to practically all countries, with the World Health Organization (WHO) declaring it a high-risk pandemic. On June 10, 2020, there were $12,102,328$ cases contaminated and 551,046 deaths due to the COVID-19. ${ }^{2}$ The coronavirus infection causes respiratory alterations and is more contagious than severe acute respiratory syndrome and the Middle East respiratory syndrome coronavirus. ${ }^{3}$

Seeking to prevent further spread, the most infected regions declared state of emergency and restrictions to the population, such as quarantine, stay-in-home orders, and lockdown. WHO, National Institutes, or Ministries of Health and National Councils are constantly publishing and updating specific guidelines for each professional area. However, the coronavirus spread has provided great challenges for Medicine and Dentistry.

The effects of coronavirus in Dentistry included several biosafety measures and recommendations due to the high risk of contamination during dental care, ${ }^{3,4}$ and in some regions, dental care was limited to urgencies and emergencies. ${ }^{5,6}$ As coronavirus is abundantly present in salivary secretions of the affected patients, ${ }^{7}$ its spread is predominantly thought to be related to respiratory droplets and aerosols. Due to the characteristics of dental care procedures, the risk of cross-infection can be high among patients, dentists, and staff. ${ }^{3}$ This way, strict and effective infection control protocols and guidelines for dental care are being recommended. ${ }^{3,89}$

All routine dental care has been suspended in many countries experiencing COVID-19 disease during the period of the pandemic. ${ }^{5,6}$ In Brazil, the Federal Council of Dentistry presented guidelines for evaluating dental urgency and emergency during the coronavirus pandemic. ${ }^{10}$ Dentists were advised to manage urgencies and emergencies only; however, the professionals can decide to maintain the dental offices open or to care only for patients with urgencies or emergencies.

The objective of this web-based survey was to assess the effects of COVID-19 pandemic on elective and urgency/emergency dental care and dentists' positions and concerns.

\section{Material and Methods}

This survey was approved by the Ethics Research Committee of the Ingá University Center Uningá, Maringá, Brazil (IRB n. 30797120.0.0000.5220).

Sample size calculation for questionnaires was performed with a confidence interval of $95 \%$ and margin of error of $5 \%$, considering the population of 338,000 dentists in Brazil, ${ }^{11}$ resulting in the need for 384 dentists answering the questionnaire.

Via WhatsApp Messenger (WhatsApp Inc., California, United States), a Google forms questionnaire was sent to dentists in Brazil, who were not identified in the survey. The questionnaire was available for responses from May 5, 2020 to May 20, 2020, when the curve of the COVID-19 contamination was still rising in Brazil.

The questions included: age, gender, dental office location, specialty, and degree of dental graduation. Besides, questions regarding what type of dental care was provided during quarantine, increase of emergencies, the biosafety routine of dental offices, among others were also included ( - Table $\mathbf{1}$ ). The levels of concern about the impact of quarantine on dental care and patient's oral health conditions and about the economic impact of quarantine on dental practices were evaluated with a 0 - to 10 -point scale.

Responses to the questionnaire were tabulated in excel, for statistical analysis.

To test the reliability of the answers, question 7 was repeated twice in the survey, because it was an important question with yes/no response. This allowed performing an intraclass correlation coefficient that showed a result of 0.91 , indicating an excellent agreement. This question was chosen because it has only three responses, including yes or no, and was a critical and important question in the survey.

Descriptive statistics were performed with percentages. Comparison of age and levels of concerns among dentists that provided routine dental care, only emergencies, or closed the dental office was performed with one-way ANOVA and Tukey tests. Association between dentists from more and less affected states with the type of dental care provided or dental office closed was performed with the chi-square test. Statistical analysis was performed with Statistica software (version 10.0, Statsoft, Tulsa, Okla, United States), and results were considered significant at $p<0.05$.

\section{Results}

As shown in - Table 1, 537 dentists, 60\% females and 38\% males, with a mean age of 38.44 years, participated in the research. Dentists were from 21 Brazilian states (26 states and 1 district capital), $41.3 \%$ live in the most affected states by COVID-19, and $58.7 \%$ from less affected states.

Among the professionals, there were general dentists and specialists from more than ten expertise areas in Dentistry. Most of them were specialists (56.8\%) with more than 10 years of clinical experience, in addition to general dentists (15.5\%), MScs (17.5\%), and PhDs (10.2\%).

During quarantine, $64.6 \%$ of the dentists attended only urgency/emergency dental care, $26.1 \%$ maintained routine appointments, and 9.3\% closed the dental offices. More dentists from the less affected states maintained routine dental care than dentists from the states with more confirmed cases of COVID-19, and this difference was statistically significant (-Fig. 1). Furthermore, dentists that maintained routine dental cares were younger and presented a significantly lower level of concern about dental treatments and oral health conditions of their patients (-Fig. 2).

Regarding urgency/emergency appointments, only $44.1 \%$ reported an increase in demand for emergency care during quarantine, and this was attributed mainly to increased patient's anxiety and stress (41.6\%) and unavailability of 
Table 1 Questionnaires and answers distributions ( $n=537)$

\begin{tabular}{|c|c|}
\hline Questions & Answers \\
\hline 1. How old are you? & Mean age $=38.44$ y $( \pm 11.20)$ \\
\hline 2. Sex/Gender & $\begin{array}{l}\text { Females } 322(60 \%) \\
\text { Males } 215(40 \%)\end{array}$ \\
\hline 3. In which state of Brazil is your dental office? & $\begin{array}{l}\text { More affected states } 222(A L=1 ; A M=1 ; C E=2 ; M A=1 ; P A=1 ; P E=1 ; R J=19 ; \\
R N=1 ; S P=191 ; S E=4) \\
\text { Less affected states } 315(B A=4 ; D F=14 ; C O=4 ; M G=25 ; M S=11 ; M T=29 \\
P I=4 ; P R=191 ; R S=15 ; S C=15 ; T O=3)\end{array}$ \\
\hline 4. What is your specialty? & $\begin{array}{l}\text { General dentistry } 105 \text { (19.6\%); Orthodontics } 104 \text { (19.4\%); Implant dentistry } 91 \\
\text { (16.9\%); Prosthetic dentistry } 58 \text { (10.8\%); Endodontics 52 (9.7\%); Restorative } \\
\text { dentistry } 36 \text { (6.7\%); Oral surgery } 22(4.1 \%) ; \text { Pediatric dentistry } 19(3.5 \%) ; \\
\text { Periodontics } 18 \text { (3.4\%); Orofacial harmonization } 16 \text { (3\%); Stomatology } 6(1.1 \%) ; \\
\text { Radiology } 5 \text { (0.9\%); Temporomandibular disorder } 3 \text { (0.6\%); Hospital dentistry } \\
2(0.4 \%) \text {. }\end{array}$ \\
\hline 5. What is your degree of dental graduation? & $\begin{array}{l}\text { General dentist } 83 \text { (15.5\%); Specialist } 305 \text { (56.8\%); Master (MSc) } 94 \text { (17.5\%); } \\
\text { Doctor (PhD) } 55 \text { (10.2\%). }\end{array}$ \\
\hline $\begin{array}{l}\text { 6. How were the dental care appointments in } \\
\text { your office during quarantine (most of the } \\
\text { time)? }\end{array}$ & $\begin{array}{l}\text { Routine care appointments were maintained } 140 \text { (26.1\%). } \\
\text { Only emergency or urgency care was scheduled } 347(64.6 \%) \text {. } \\
\text { Dental office closed; no orthodontic care provided } 50(9.3 \%) .\end{array}$ \\
\hline $\begin{array}{l}\text { 7. Was there an increase in dental emergencies } \\
\text { in your office during this period? }\end{array}$ & $\begin{array}{l}\text { Yes } 237(44.1 \%) \\
\text { No } 300(55.9 \%)\end{array}$ \\
\hline $\begin{array}{l}\text { 8. What do you think that caused increase in } \\
\text { dental emergencies? }\end{array}$ & $\begin{array}{l}\text { Increased patient's anxiety and stress } 128(41.6 \%) \text {. } \\
\text { Absence of routine/elective dental care } 161(52.3 \%) \text {. } \\
\text { Others } 19(6.1 \%)\end{array}$ \\
\hline $\begin{array}{l}\text { 9. What were the main causes of emergency } \\
\text { dental care? (select all that apply) }\end{array}$ & $\begin{array}{l}\text { Toothache } 362 \text { (71.4\%); Broken restorations } 205 \text { (40.4\%); Anterior tooth frac- } \\
\text { ture/Dental trauma } 189 \text { ( } 37.3 \%) \text {; Posterior tooth fracture } 161 \text { ( } 31.8 \%) \text {; Breakage } \\
\text { of orthodontic appliance } 128 \text { (25.2\%); Temporomandibular disorders } 48 \text { (9.5\%); } \\
\text { Emergencies related to poor oral hygiene } 45 \text { (8.9\%). }\end{array}$ \\
\hline $\begin{array}{l}\text { 10. How did your patient get in touch to schedule } \\
\text { the emergency care? (Select all that apply) }\end{array}$ & $\begin{array}{l}\text { Messages to the dental office's WhatsApp } 358 \text { (70.6\%). } \\
\text { Dental office's phone call } 249 \text { (49.1\%). } \\
\text { Personal dentist's phone call and/or WhatsApp message } 195 \text { (38.5\%). } \\
\text { Dental office webpage on social networks } 73 \text { (14.4\%). } \\
\text { Personal dentist's webpage on social networks } 42 \text { (8.3\%). }\end{array}$ \\
\hline $\begin{array}{l}\text { 11. What is your level of concern about the } \\
\text { impact of quarantine on dental care and the } \\
\text { oral health condition of your patients? }\end{array}$ & Mean $=8.09( \pm 2.05)$ \\
\hline $\begin{array}{l}\text { 12. With the pandemic, was there a change in the } \\
\text { biosafety routine of the office? }\end{array}$ & $\begin{array}{l}\text { Yes } 506(95.5 \%) \\
\text { No } 24(4.5 \%)\end{array}$ \\
\hline $\begin{array}{l}\text { 13. Did you provide dental care (emergency or } \\
\text { not) accompanied by your staff? }\end{array}$ & $\begin{array}{l}\text { Yes } 220(41.5 \%) \\
\text { No } 310(58.5 \%)\end{array}$ \\
\hline $\begin{array}{l}\text { 14. Did your patients seek for elective/routine } \\
\text { dental care? }\end{array}$ & $\begin{array}{l}\text { Yes } 450(83.8 \%) \\
\text { No } 87(16.2 \%)\end{array}$ \\
\hline $\begin{array}{l}\text { 15. Which elective/routine dental care were most } \\
\text { frequently sought during quarantine? (Select } \\
\text { all that apply) }\end{array}$ & $\begin{array}{l}\text { Prophylaxis and preventive procedures } 241 \text { (49.1\%) } \\
\text { Esthetic restorations } 196(39.9 \%) \\
\text { Orthodontic treatment } 177(36 \%) \\
\text { Prosthesis installation } 174(35.4 \%) \\
\text { Surgery; teeth extraction } 132(26.9 \%) \\
\text { Implant placement } 97(19.8 \%) \\
\text { Teeth whitening } 72(14.7 \%) \\
\text { Orofacial esthetic procedures } 42(8.6 \%)\end{array}$ \\
\hline $\begin{array}{l}\text { 16. What is your level of concern about the eco- } \\
\text { nomic impact of quarantine/pandemic on } \\
\text { your dental practice? }\end{array}$ & Mean $=9.03( \pm 1.62)$ \\
\hline $\begin{array}{l}\text { 17. During the quarantine period, did you dismiss } \\
\text { your staff? }\end{array}$ & $\begin{array}{l}\text { Yes, they took a vacation } 193 \text { ( } 35.9 \%) \text {. } \\
\text { Yes, but they were at home-office } 188 \text { (22\%). } \\
\text { No, they continued to work routinely in the dental office } 129 \text { (24\%). } \\
\text { Staff suspended from activities with government assistance } 67 \text { (12.5\%). } \\
\text { I had to fire my employee(s) } 30 \text { (5.6\%). }\end{array}$ \\
\hline
\end{tabular}




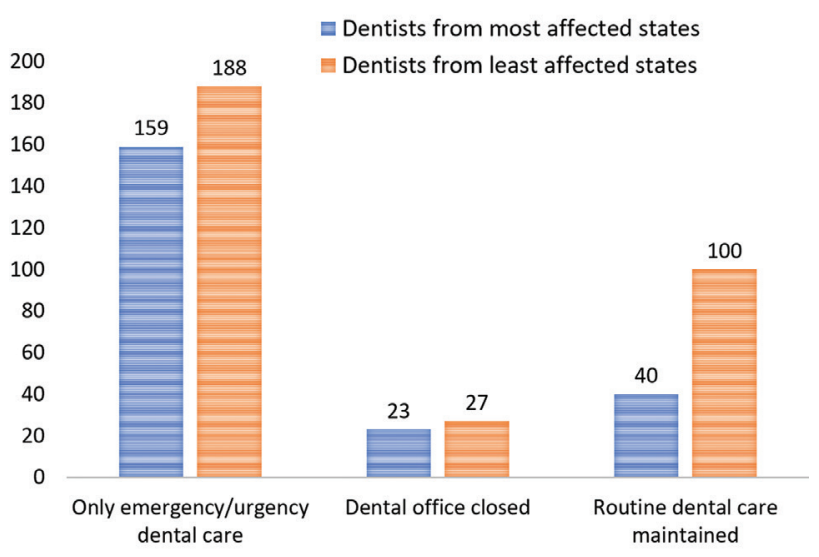

Fig. 1 Association between dentists from most or least affected states and type of dental care provided or dental office closed $(p<0.000)$.

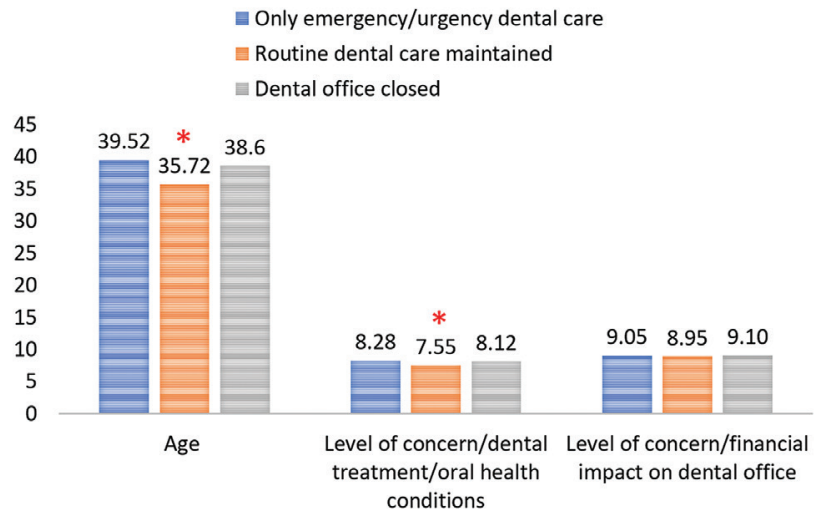

Fig. 2 Comparison of age, and levels of concerns among dentists that provided routine dental care, only emergencies or closed the dental office (asterisk indicates the presence of a statistically significant difference, $p<0.000)$.

routine/elective dental care (52.3\%). The main causes of urgencies/emergencies were toothache (71.4\%), broken restorations (40.4\%), dental trauma (37.3\%), breakage of orthodontic appliance (25.2\%), and temporomandibular disorders (TMD) (9.5\%). Most patients got in touch to schedule the emergency appointment by message to the dental office's WhatsApp (70.6\%), a phone call to the dental office (49.1\%), and through message or call to the dentist's personal phone (38.5\%).

The mean level of concern of the dentists about the impact of quarantine on dental care and patient oral health condition was 8.09 in a 0 -to-10-point scale (-Fig. 3 ).

Almost all dentists (95.5\%) changed the biosafety protocols of the dental offices to reduce the risk of coronavirus spread, and most of them (58.5\%) attended emergency appointments without staff.

Most professionals (83.8\%) reported that patients sought elective dental care, and most of them were adults (87.8\%). In this situation, $54 \%$ of the dentists performed elective/routine procedures. The most sought elective procedures were prophylaxis and preventive procedures (49.1\%), esthetic restorations (39.9\%), orthodontic treatment (36\%), prosthesis installation (35.4\%), teeth extraction (26.9\%), implant

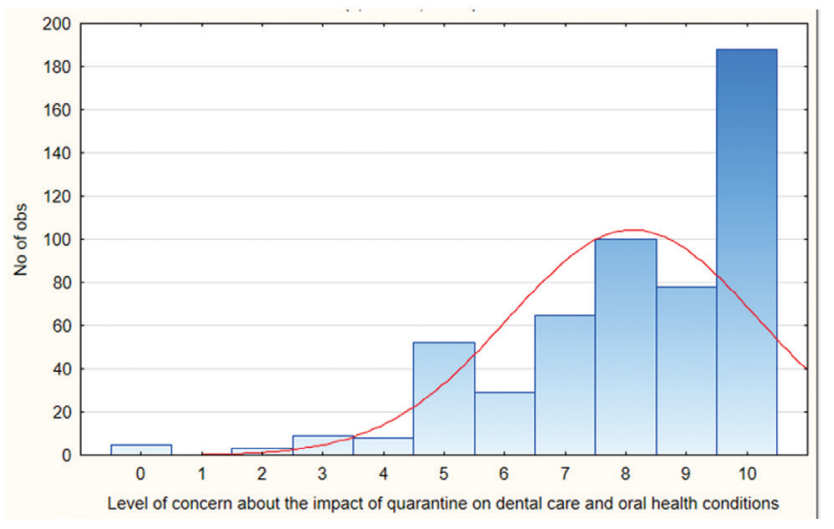

Fig. 3 Histogram of the level of concern about the impact of quarantine on dental care and the oral health condition of the patients.

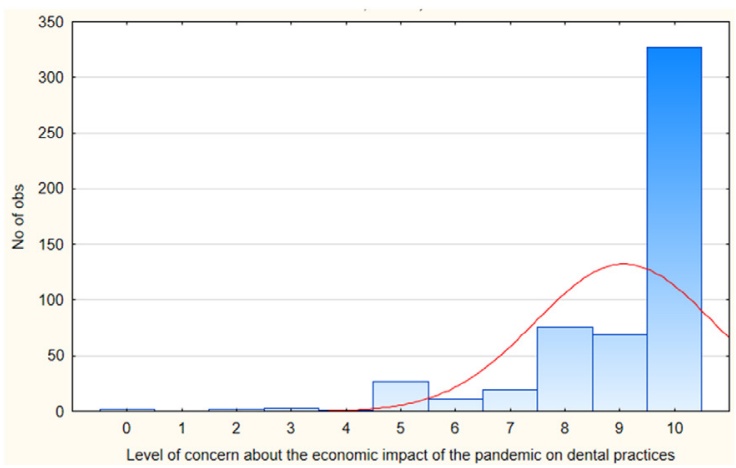

Fig. 4 Histogram of the level of concern about the economic impact of quarantine/pandemic on dental practices.

placement (19.8\%), teeth whitening (14.7\%), and orofacial esthetic procedures (8.6\%).

The mean level of concern about the economic impact of quarantine on dental practices was 9.03 (-Fig. 4). Moreover, $35.9 \%$ of the dentists gave their employees vacations, or they were maintained at home-office (22\%). Only $24 \%$ of the employees maintained regular work at the dental office, $12.5 \%$ were suspended from activities with government assistance, and $5.6 \%$ were fired.

\section{Discussion}

Brazil is a continental country. Disregarding the Russian territory, Europe has a territorial extension similar to Brazil. Consequently, the regions of Brazil were affected in different ways and intensities by COVID-19, and the most affected were southeast (population: 85 million people) and northeast regions (population: 50 million). ${ }^{12}$ To avoid the coronavirus spread, Federal and State governments declared the quarantine period as a restrictive social contact protocol. Two hundred and twenty-two dentists (41\%), who answered the questionnaire, live in the most affected states, while the remaining 315 professionals (59\%) live in the least affected states (-Table 1). 
In dental care, the fear of dissemination of COVID-19 and the need for time to implement a novel biosafety protocol motivated the dentists to reduce elective procedures. In the beginning, there was not much information on how to deal with dental care appointments, especially for urgencies and emergencies. Currently, according to the present results, 95.5\% of the professionals reinforced biosafety protocols of dental offices, such as the use of face shields and disposable personal protective equipment discarded after each appointment, improved suction to avoid aerosols/droplets dispersion, mouth rinsing with chlorhexidine before dental procedures, rubber damn isolation, and increase in time between dental care appointments. Dentists and dental staff reinforced the handwashing procedures, equipment disinfection using sodium hypochlorite, and mandatory use of disposable masks all the time.

Patients were instructed to wear disposable shoes cover and to clean their hands with $70 \%$ alcohol at the entrance door. As the incubation period of COVID-19 is up to 14 days, ${ }^{13,14}$ dental staff triage patients before the schedule regarding symptoms or contact with COVID-19 diagnosed people. If necessary, the appointment would be postponed. Body temperature is measured before the dental procedure looking for asymptomatic patients. These protective measures allowed some dentists to maintain routine dental care (only $26.1 \%$ maintained routine/elective appointments) since the population is feeling more secure and safer as more information regarding COVID-19 is published.

Most dentists (64.6\%) who answered the questionnaires attended only urgencies/emergencies during quarantine, and $58.5 \%$ provided dental care without staff. According to the present survey, a higher percentage of dental professionals from less affected states maintained routine dental care compared with dentists who live in states with more confirmed cases of COVID-19, and this difference was statistically significant (-Fig. 1). Besides, dentists that maintained routine dental care were younger and less concerned with the dental treatments to be performed, as well as with the patient oral health than dentists that closed dental offices or provided only emergency dental care ( - Fig. 2). Younger people reported lower anxiety levels with the pandemic in a previous study, may be because older people are facing greater family and job concerns, and financial worries. ${ }^{15}$ This lower level of concern may also be related to the continuity of dental treatments that started before the COVID-19 outbreak/quarantine protocols and the confidence that the reinforced biosafety protocols would be an effective protocol to provide a safe environment for dental appointments.

It registered an increase in urgency/emergency procedures by $44.1 \%$ of the dentists, mostly due to the unavailability of routine/elective dental care and increased patient anxiety and stress. During the quarantine period, $71.4 \%$ of dental appointments were related to toothache, a clinical condition that cannot be postponed. Other leading causes of urgency/emergency appointments were dental trauma and broken restorations were the main causes of dental appointments. However, these conditions are common in urgent dental appointments. ${ }^{16}$ Emergencies related to the breakage of orthodontic appliances are possibly due to the increased or delayed interval between appointments imposed by the quarantine. ${ }^{17,18}$ TMDs were related to $9.5 \%$ of the dentists as the cause of emergency dental care during the quarantine. This may be related to increased patient's anxiety and stress during the pandemic/quarantine. ${ }^{19,20}$ Some psychological disturbances are important risk factors for the development of signs and symptoms of TMD. ${ }^{21}$

In this sense, teledentistry can be used to help to relieve patient's anxiety and stress, like tips for maintaining oral health, avoiding the need for a face-to-face dental appointment, ${ }^{22}$ since most dental problems can be prevented with regular dental care and steps to minimize risks of oral trauma. ${ }^{16}$ Some urgencies in dentistry will need face-to-face appointments, but focus on high-quality nonvisit care would work well for many patients. ${ }^{23}$

A very interesting data are that, despite the stay-in-home recommendations, $83.8 \%$ of the dentists reported that their patients sought for elective dental care, like prophylaxis and preventive procedures (49.1\%). Patients may have sought for elective dental treatment because they are not respecting the quarantine as recommended by the local authorities or probably because patients live in states with lower COVID-19 incidence. Also, the population may not entirely respect or agree with less social distance. ${ }^{22}$ Another probable cause for this great demand for elective and preventive procedures may be due to fear of worsening of the pandemic, and consequently, fear by the patients of not being able to receive any dental treatment in the next months.

Some procedures, like prophylaxis, the most sought elective dental care by the patients, cause great production of aerosols, thus increasing the chances of contamination. Dental procedures involving aerosols should be avoided in places during the COVID-19 outbreak. Besides, in addition to standard precautions, some special precautionary measures should also be implemented during this special period. ${ }^{24}$

During these difficult times, we must ethically decide whether or not to maintain dental care, taking into account the needs of patients and also the protection of dental staff, patients, and the entire community. However, shutting down, even temporarily, is a cause for concern not just for patients but for dentists that reported a high level of concern about the economic impact of the quarantine on dental practices, as well as those of their staff members. In addition to the economic concern, some dentists have expressed their intention to continue the day-to-day practice. This may have been motivated, in part, by a sense of avoiding harm to employees who would have their income reduced if the practice is not able to meet payroll for a period.

\section{Conclusions}

COVID-19 caught governments and people off guard. The purpose of quarantine is to reduce social contact so that the spread of the virus decreases, thus preventing those hospitals from being overwhelmed. On the other hand, self-employed professionals need to work to maintain their companies and families. The pandemic/quarantine has negatively affected the clinical routine of dental offices, and 
personal protection/hygiene care must be adopted and reinforced by dental professionals/staff and patients to make the dental procedures safer.

\section{Conflict of Interest}

None declared.

\section{References}

1 Wang X, Zhang X, He J. Challenges to the system of reserve medical supplies for public health emergencies: reflections on the outbreak of the severe acute respiratory syndrome coronavirus 2 (SARS-CoV-2) epidemic in China. Biosci Trends 2020;14(1):3-8

2 World Health Organization. Coronavirus disease (COVID-19). Situation report -172; 2020. Available at: https://www.who. int/docs/default-source/coronaviruse/situation-reports/20200710-covid-19-sitrep-172.pdf?sfvrsn=70724b90_2. Accessed July 10, 2020

3 Meng L, Hua F, Bian Z. Coronavirus disease 2019 (COVID-19): emerging and future challenges for dental and oral medicine. J Dent Res 2020;99(5):481-487

4 Ather A, Patel B, Ruparel NB, Diogenes A, Hargreaves KM. Coronavirus disease 19 (COVID-19): implications for clinical dental care. J Endod 2020;46(5):584-595

5 Coulthard P. Dentistry and coronavirus (COVID-19)-moral decision-making. Br Dent J 2020;228(7):503-505

6 Spagnuolo G, De Vito D, Rengo S, Tatullo M. COVID-19 outbreak: an overview on dentistry. Int J Environ Res Public Health 2020;17(6):2094

7 Hamid H, Khurshid Z, Adanir N, Zafar MS, Zohaib S. COVID19 pandemic and role of human saliva as a testing biofluid in point-of-care technology 2020. Eur J Dent:2020;14(suppl S1):S123-S129 doi:10.1055/s-0040-1713020

8 Larson EL, Early E, Cloonan P, Sugrue S, Parides M. An organizational climate intervention associated with increased handwashing and decreased nosocomial infections. Behav Med 2000;26(1):14-22

9 World Health Organization. Questions and answers on coronaviruses; 2020. Available at: https://www.who.int/news-room/ q-a-detail/q-acoronaviruses. Accessed February 26, 2020

10 Federal Council of Dentistry. FCD presents guidelines for evaluating dental urgency and emergency against Coronavirus; 2020. Available at: http://website.cfo.org.br/cfo-apresenta-orientacoes-para-avaliar-urgencia-e-emergencia-odontologica-frente-ao-coronavirus/. Accessed April 26, 2020
11 Federal Council of Dentistry. General Number of Specialist Dental Surgeons; 2020. Available at: http://website.cfo.org.br/estatisticas/ quantidade-geral-de-cirurgioes-dentistas-especialistas

12 Brazilian Ministry of Health. Coronavirus panel; 2020. Available at: https://covid.saude.gov.br/. Accessed May 2, 2020

13 Backer JA, Klinkenberg D, Wallinga J. Incubation period of 2019 novel coronavirus (2019-nCoV) infections among travellers from Wuhan, China, 20-28 January 2020. Euro Surveill 2020;25(5):25

14 Li Q, Guan X, Wu P, et al. early transmission dynamics in Wuhan, China, of novel coronavirus-infected pneumonia. N Engl J Med 2020;382(13):1199-1207

15 Jungmann SM, Witthöft M. Health anxiety, cyberchondria, and coping in the current COVID-19 pandemic: which factors are related to coronavirus anxiety? J Anxiety Disord 2020;73:102239

16 Douglass AB, Douglass JM. Common dental emergencies. Am Fam Physician 2003;67(3):511-516

17 Dowsing P, Murray A, Sandler J. Emergencies in orthodontics. Part 1: management of general orthodontic problems as well as common problems with fixed appliances. Dent Update 2015 42(2):131-134, 137-140

18 Caprioglio A, Pizzetti GB, Zecca PA, Fastuca R, Maino G, Nanda R. Management of orthodontic emergencies during 2019-NCOV. Prog Orthod 2020;21(1):10

19 Almeida-Leite CM, Stuginski-Barbosa J, Conti PCR. How psychosocial and economic impacts of COVID-19 pandemic can interfere on bruxism and temporomandibular disorders? J Appl Oral Sci 2020;28:e20200263

20 Peng X, Xu X, Li Y, Cheng L, Zhou X, Ren B. Transmission routes of 2019-nCoV and controls in dental practice. Int J Oral Sci 2020;12(1):9

21 De La Torre Canales G, Câmara-Souza MB, Muñoz Lora VRM, et al. Prevalence of psychosocial impairment in temporomandibular disorder patients: a systematic review. J Oral Rehabil 2018;45(11):881-889

22 Cotrin P, Peloso RM, Oliveira RC, et al. Impact of coronavirus pandemic in appointments and anxiety/concerns of patients regarding orthodontic treatment. Orthod Craniofac Res 2020

23 Duffy S, Lee TH. In-person health care as option B. N Engl J Med 2018;378(2):104-106

24 Ge ZY, Yang LM, Xia JJ, Fu XH, Zhang YZ. Possible aerosol transmission of COVID-19 and special precautions in dentistry. J Zhejiang Univ Sci B 2020;21(5):361-368 